\title{
Efektivitas Kompres Daun Kubis (Brassica Oleracea) terhadap Skala Pembengkakan Payudara pada Ibu Post Partum di PMB Endang Kota Kediri
}

\author{
Miftakhur Rohmah ${ }^{1}$, Anggrawati Wulandari ${ }^{2}$, Deny Wati Sihotang ${ }^{3}$ \\ 1,2 Dosen Institut Ilmu Kesehatan STRADA Indonesia \\ ${ }^{3}$ Mahasiswi Program DIV-Kebidanan Institut Ilmu Kesehatan STRADA Indonesia \\ Corresponding author: Miftakhur Rohmah (m1111ftaa@gmail.com)
}

Received 16 August 2019; Accepted 20 August 2019; Published 5 September 2019

\begin{abstract}
ABSTRAK
Pembengkakan payudara merupakan hambatan dalam pemberian ASI, masalah ini semakin meningkat kejadiannya sehingga diperlukan penanganan yang lebih nyaman bagi ibu dalam mengatasi masalah ini. Diperlukan metode yang efektif dalam mengatasi masalah ini agar ibu dapat memberikan ASI secara eksklusif pada bayinya. Kubis kaya akan kandungan sulfur yang dapat mengurangi pembengkakan dan peradangan payudara. Tujuan penelitian ini menganalisis efektivitas pemberian kompres daun kubis (brassica oleracea) terhadap skala pembengkakan payudara pada ibu post partum di PMB Endang Kota Kediri. Desain penelitian ini Quasi Experiment dengan desain eksperimen One Group Pratest Posttest. Sampel dalam penelitian ini adalah 25 ibu postpartum yang mengalami pembengkakan payudara dengan teknik pengambilan sampel Accidental Sampling, alat pengumpulan data menggunakan Checklist six-point engorgement scale dan wawancara singkat. Uji statistik menggunakan Uji Wilcoxon. Hasil penelitian menunjukkan bahwa ada efektivitas pemberian kompres daun kubis (brassica oleracea) terhadap skala pembengkakan payudara pada ibu post partum dapat dilihat dari penurunan pembengkakan payudara sebelum diberikan kompres daun kubis (brassica oleracea) yaitu skala 4, sesudah diberikan kompres daun kubis (brassica oleracea) pembengkakan payudara menjadi skala 1 dengan p-value 0,000 ( $\square=0,05)$. Kompres daun kubis (brassica oleracea) dapat digunakan sebagai terapi untuk menurunkan skala pembengkakan dan mencegah terjadinya pembengkakan payudara pada ibu post partum.
\end{abstract}

Kata Kunci: Skala pembengkakan payudara, Kompres daun kubis (brassica oleracea), Ibu Post Partum

Copyright @ 2019 Institut Ilmu Kesehatan STRADA Indonesia All rights reserved.

This is an open-acces article distributed under the terms of the Creative Commons Attribution-ShareAlike 4.0 International License. 


\section{PENDAHULUAN}

Masa nifas (puerperium) dimulai setelah plasenta lahir dan berakhir ketika alat-alat kandungan kembali seperti keadaan sebelum hamil. Masa nifas berlangsung selama kira-kira 6 minggu atau 42 hari, namun secara keseluruhan akan pulih dalam waktu 3 bulan. Masa nifas atau post partum disebut juga puerperium yang berasal dari bahasa latin yaitu dari kata "Puer" yang artinya bayi dan "Parous" berarti melahirkan (Zuhana, 2014).

ASI yang tidak diberikan secara adekuat akan mengakibatkan terjadinya pembengkakan pada payudara, sehingga sisa ASI terkumpul pada daerah duktus laktoferus. Hal ini dapat terjadi pada hari ke tiga setelah melahirkan. Selain itu, penggunaan bra yang ketat serta keadaan puting susu yang tidak bersih dapat menyebabkan sumbatan pada duktus. Dan apabila tidak ada intervensi yang baik karena terjadinya pembengkakan payudara akan menimbulkan puting susu lecet, mastitis, dan abses payuda hingga sampai menimbulkan septicemia (Ririn, 2017).

Berdasarkan laporan dari Survei Demografi dan Kesehatan Indonesia (SDKI, 2016) diusia lebih dari 25 tahun sepertiga wanita di Dunia (38\%) didapati tidak menyusui bayinya karena terjadi pembengkakan payudara, dan di Indonsia angka cakupan ASI eksklusif mencapai 32,3\% ibu yang memberikan ASI eksklusif pada anak mereka. Sebanyak 55\% ibu menyusui mengalami mastitis dan puting susu lecet, kemungkinan hal tersebut disebabkan karena kurangnya perawatan payudara selama kehamilan.

Menurut Dinas Kesehatan Propinsi Jawa Timur ada 58\% ibu nifas yang mengalami masalah dalam menyusui, yaitu 23\% mengalami pembengkakan payudara, 13\% putting susu tenggelam, $9 \%$ putting susu lecet, $7 \%$ mastitis dan $6 \%$ abses payudara sehingga pemberian ASI pada bayi mengalami penurunan (Naning, 2015). Data dari Dinas Kesehatan Kota Kediri pada tahun 2015 cakupan ibu nifas 13.319 orang ibu nifas, dan ibu nifas yang mendapat pelayanan kesehatan 11.666 orang ibu nifas atau sebanyak 87,59\% dari cakupan ibu nifas (Dinkes, 2015).

Berdasarkan hasil studi pendahulan pada bulan Februari 2018 di PMB Endang, diperoleh jumlah ibu post partum sebanyak 10 orang. Ibu post partum yang mengalami pembengkakan payudara di daerah tersebut sebanyak 7 orang pada hari ke 3-4. Sebanyak 5 orang ibu post partum mengalami pembengkakan payudara diakibatkan karena kurangnya pemberian ASI secara adekuat dan 2 orang ibu post partum mengalami pembengkakan payudara diakibatkan karena penggunaan bra yang ketat.

Penanganan pembengkakan payudara dapat dilakukan secara farmakologis dan non farmakologis. Penanganan pembengkakan payudara secara farmakologis dapat diberikan terapi simtomatis untuk mengurangi rasa sakitnya (analgetik) seperti paracetamol, ibuprofen. Dapat juga diberikan lynoral tablet 3 kali sehari selama 2-3 hari untuk membendung sementara produksi ASI. Dan untuk mengurangi pembengkakan payudara secara non farmakologis dapat dilakukan dengan akupuntur, perawatan payudara tradisional (kompres panas dikombinasikan dengan pijatan), daun kubis, kompres panas dan dingin secara bergantian, kompres dingin, dan terapi ultrasound (Marmi, 2012).

Kubis mempunyai sifat antibiotik dan anti-inflamasi karena kandungan sinigrin (Allylisothiocyanate), rapine, minyak mustard, magnesium, dan sulfur yang dapat membantu memperlebar pembuluh darah kapiler, sehingga meningkatkan aliran darah untuk keluar masuk dari daerah tersebut, dan memungkinkan tubuh untuk menyerap kembali cairan yang terbendung dalam payudara tersebut (Teori Mars, 2014).

Berdasarkan latar belakang diatas peneliti tertarik untuk melakukan penelitian tentang Efektivitas Kompres Daun Kubis (Brassica Oleracea) Terhadap Skala Pembengkakan Payudara Ibu Post partum di PMB Endang Kota Kediri. Penelitian ini bertujuan untuk menganalisis efektitivitas kompres daun kubis (Brassica Oleracea) terhadap skala pembengkakan payudara pada ibu post partum di PMB Endang Kota Kediri. 


\section{METODE}

Menurut metode penelitian, penelitian ini merupakan penelitian eksperimen semu (Quasi Experimen) dengan rancangan penelitian One Group Pratest Posttest yaitu rancangan eksperimen yang dilakukan pada satu kelompok saja tanpa kelompok pembanding.

Populasi dalam penelitian ini adalah ibu post partum di PMB Endang Kota Kediri sebanyak 58 orang. Sampel dalam penelitian ini adalah sebagian ibu post partum yang mengalami pembengkakan payudara di PMB Endang Kota Kediri sebanyak 25 orang.

Teknik sampling yang digunakan pada penelitian ini adalah teknik Accidental Sampling yaitu memilih ibu post partum yang mengalami pembengkakan payudara untuk dijadikan sebagai sampel pada penelitian.

Instrumen yang digunakan pada penelitian ini adalah lembar kuesioner dan lembar observasi. Skala pembengkakan diukur menggunakan check list six point engorgement scale (SPES) diambil sebelum dan sesudah diberikan perlakuan. Pemberian daun kubis diberikan sesuai dengan SOP, dengan cara menempelkan daun kubis pada kedua payudara yang mengalami bengkak dan dimasukan kedalam BH selama 10-15 menit, dilakukan sehari 3x. Kemudian data diolah menggunakan SPSS dengan Uji Wilcoxon.

\section{HASIL}

\section{Karakteristik responden}

Tabel 3.1 Distribusi frekuansi karakteristik responden

\begin{tabular}{lll}
\hline Karakteristik & jumlah & \% \\
\hline Usia ibu & & \\
$<25$ tahun & 5 & $20 \%$ \\
$25-35$ ahun & 16 & $64 \%$ \\
$>35$ tahun & 4 & $16 \%$ \\
\hline Pendidikan ibu & 2 & $8 \%$ \\
SD & 2 & $20 \%$ \\
SMP & 5 & $48 \%$ \\
SMA & 12 & $24 \%$ \\
PT & 6 & \\
Pekerjaaan ibu & & $56 \%$ \\
IRT & 14 & $36 \%$ \\
Wiraswasta & 9 & $8 \%$ \\
PNS & 2 & \\
& & \\
Paritas & & $52 \%$ \\
Primipara & 13 & $32 \%$ \\
Multipara & 8 & $16 \%$ \\
Grandemultipara & 4 & \\
\hline
\end{tabular}

Berdasarkan tabel diatas dapat diketahui bahwa sebagian besar (64\%) ibu yang mengalami pembengakkan adalah di usia 25-35 tahun, pendidikan hampir setangah responden (48\%) berpendidikan SMA, Sebagian besar responden (56\%) memiliki pekerjaan IRT, dan paritas sebagian besar $(52 \%)$ adalah Primipara. 


\section{Karakteristik Variabel}

1. Skala Pembengkakan Payudara Sebelum Diberikan Kompres Daun Kubis (Brassica Oleracea)

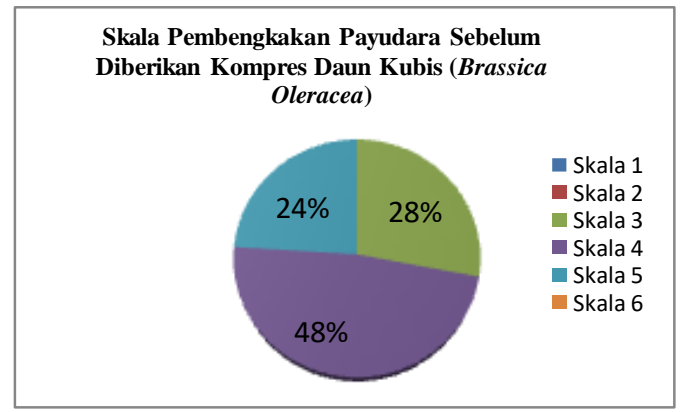

Sumber: Data Primer Kuisioner 2018

Gambar 4.7 Skala Pembengkakan Payudara Sebelum Diberikan Kompres Daun Kubis (Brassica Oleracea)

Dari 25 total responden terdapat hampir sebagian dari (48\%) 12 responden mengalami pembengkakan payudara skala 4 sebelum diberikan kompres daun kubis (brassica oleracea).

2. Skala Pembengkakan Payudara Sesudah Diberikan Kompres Daun Kubis (Brassica Oleracea)

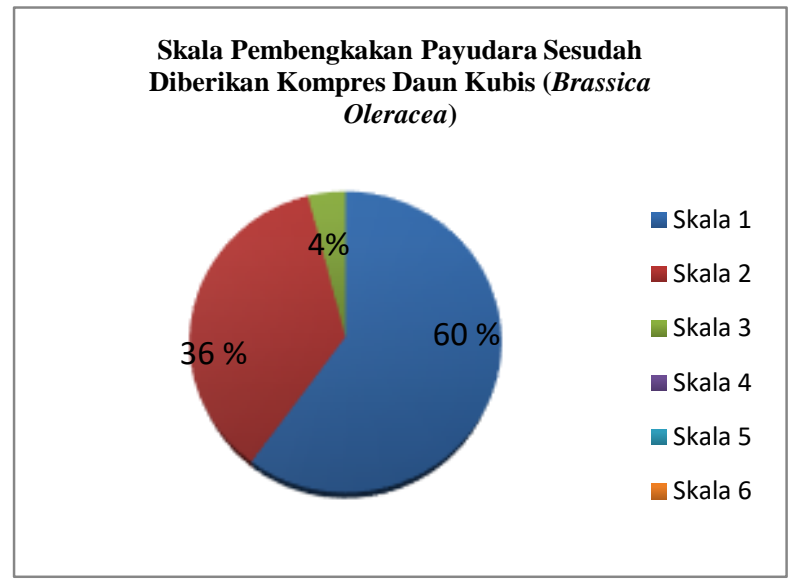

Sumber: Data Primer Kuisioner 2018

Gambar 4.8 Skala Pembengkakan Payudara Sebelum Diberikan Kompres Daun Kubis (Brassica Oleracea)

Dari total 25 responden terdapat sebagian besar (60\%) 15 responden mengalami pembengkakan payudara skala 1 sesudah diberikan kompres daun kubis (Brassia Oleracea). 


\section{Hasil Uji Statistik}

Uji statistik untuk mengetahui efektivitas pemberian kompres daun kubis (brassica oleracea) terhadap skala pembengkakan payudara pada ibu post partum dengan menggunakan uji Wilcoxon. Tabel 4.12 Hasil uji statistik efektivitas pemberian kompres daun kubis (brassica oleracea) terhadap skala pembengkakan payudara pada ibu post partum di PMB Endang Kota Kediri.

Test Statistics ${ }^{\mathrm{a}}$

\begin{tabular}{lr}
\hline & Sesudah - Sebelum \\
\hline$Z$ & $-4,507^{\mathrm{b}}$ \\
\hline Asymp. Sig. (2-tailed) &, 000 \\
\hline
\end{tabular}

a. Wilcoxon Signed Ranks Test

b. Based on positive ranks.

Berdasarkan tabel 4.12 diperoleh nilai $p$-value sebesar 0,000 atau $p$-value $<\alpha$ $(0,000<0,005)$, artinya $\mathrm{H}_{\mathrm{o}}$ ditolak dan $\mathrm{H}_{\mathrm{i}}$ diterima yang berarti pemberian kompres daun kubis (brassica oleracea) efektiv menurunkan skala pembengkakan payudara pada ibu post partum di PMB Endang Kota Kediri.

\section{PEMBAHASAN}

\section{A. Skala Pembengkakan Payudara Sebelum Diberikan Kompres Daun Kubis (Brassica Oleracea)}

Dari 25 total responden terdapat hampir sebagian dari (48\%) 12 responden mengalami pembengkakan payudara skala 4 sebelum diberikan kompres daun kubis (brassica oleracea). ibu post partum yang mengalami pembengkakan payudara yaitu pada masa post partum hari ke 3 . Hal ini terjadi akibat kurangnya pemberian ASI pada bayi secara adekuat yang menyebabkan penyumbatan pada saluran ASI karena tidak dikosongkan seluruhnya. ASI akan terus diproduksi, apabila terjadi penyumbatan pada saluran ASI dan tidak mendapat penanganan maka akan mengakibatkan terjadinya mastitis sampai abses payudara.

\section{B. Skala Pembengkakan Payudara Sesudah Diberikan Kompres Daun Kubis (Brassica Oleracea).}

Hasil penelitian dari 25 total responden terdapat sebagian besar $(60 \%) 15$ responden mengalami pembengkakan payudara skala 1 sesudah diberikan kompres daun kubis (brassica oleracea). Menurut pendapat peneliti bahwa kandungan kubis mempunyai sifat antibiotik dan antiinflamasi yang dapat membantu memperlebar pembuluh darah kapiler, sehingga meningkatkan aliran darah untuk keluar masuk dari daerah tersebut, dan memungkinkan tubuh untuk menyerap kembali cairan yang terbendung dalam payudara tersebut. Hal ini sejalan dengan teori Mars, bahwa kubis mempunyai kandungan asam amino glutamin yang bersifat sebagai antibiotik dan antiinflamasi karena kandungan yang terdapat didalamnya sehingga dapat membantu pelebaran pembuluh darah kapiler. Dan daun kubis dapat mengurangi pembengkakan untuk pemakaian luar dengan cara pengompresan. 


\section{Efektivitas Pemberian Kompres Daun Kubis(Brassica Oleracea) Terhadap Skala Pembengkakan PayudaraPada Ibu Post Partum di PMBndang Kota Kediri.}

Diperoleh nilai $p$-value sebesar 0,000 atau $p$-value $<\alpha(0,000<0,005)$, artinya $\mathrm{H}_{\mathrm{o}}$ ditolak dan Hi diterima yang berarti pemberian kompres daun kubis (brassica oleracea) efektiv menurunkan skala pembengkakan payudara pada ibu post partum di PMB Endang Kota Kediri.

Kompres yang dilakukan berguna untuk mengatatasi nyeri dan mengurangi oedema. Kompres daun kubis digunakan untuk membuat siklus vasokontriksi selama 9-16 menit, dimana aliran darah menurun sehingga oedema lokal dapat menurun dan pengaliran lympatic dapat lebih optimal (Bahiyatun, 2015).

Menurut pendapat peneliti bahwa daun kubis (brassica olerace) memiliki efektivitas dalam mengurangi pembengkakan payudara pada ibu post partum karena daun kubis (brassica olerace) mengeluarkan gel dingin yang dapat menyerap panas dan mengurangi pembengkakan. Hal ini sejalan dengan teori Bahiyatun karena kandungan yang terdapat dalam daun kubis sehingga terjadi proses pelebaran aliran pembuluh darah kapiler untuk mengurangi pembengkakan pada payudara.

\section{KESIMPULAN}

Berdasarkan penelitian yang dilakukan di PMB Endang dapat disimpulkan sebagai berikut:

1. Skala pembengkakan payudara ibu post partum sebelum diberikan kompres daun kubis (brassica oleracea) hampir sebagian (48\%) 12 responden mengalami pembengkakan payudara skala 4.

2. Skala pembengkakan payudara ibu post partum sesudah diberikan kompres daun kubis (brassica oleracea) sebagian besar (60\%) 15responden mengalami pembengkakan payudara skala 1 .

3. Pemberian kompres daun kubis (brassica oleracea) efektiv menurunkan skala pembengkakan payudara pada ibu post partum di PMB Endang Kota Kediri dengan nilai $p$-value sebesar 0,000atau $p$ value $<\alpha(0,000<0,005)$, artinya $\mathrm{H}_{\mathrm{o}}$ ditolak dan $\mathrm{Hi}$ diterima.

\section{Saran}

1. Bagi Institusi Penelitian

Diharapkan agar menjadikan hasil penelitian ini sebagai tambahan referensi dan wacana di lingkungan pendidikan serta sebagai bahan kajian lebih lanjut, khususnya untuk penelitian yang sejenisnya.

\section{Bagi Masyarakat}

Diharapkan dapat menjadi alternatif pengobatan secara non farmakologis dalam mengurangi skala pembengkakan payudara pada ibu post partum.

\section{Tempat Penelitian}

Diharapkan PMB Endang Kota Kediri secara kontiyu melakukan skrining kesehatan, home care serta lebih aktif dalam meningkatkan keikutsertaan ibu post partum dalam melakukan kunjungan selama masa nifas untuk mendapat informasi serta mendeteksi masalah-masalah yang dialami ibu selama masa nifas khususnya pada pembengkakan payudara. 


\section{Bagi Responden}

Bagi ibu post partum agar dapat menerapkan kompres daun kubis (brassica oleracea) apabila terjadi pembengkakan payudara.

\section{Bagi Peneliti Selanjutnya}

Diharapkan menjadi masukan bagi peneliti selanjutnya dalam melakukan penelitian yang lebih akurat lagi untuk mengurangi pembengkakan payudara pada ibu post partum dan disarankan untuk diuji klinis.

\section{REFERENSI}

Bobak, I., M., Lowdermilk, D., L., \& Jensen, M., D. (2012). Maternity nursing. 4th ed. (Wijayarini, M.A \& Anugrah, P.I., Penerjemah) California: CV. Mosby (sumber asli diterbitkan tahun 1995).

Dalimartha, S., \& Adrian, F. (2011). Khasiat Buah dan Sayur. Jakarta: Penebar Swadaya Grup.

Davis, \& Marie. (2014). Engorgement: the Cabbage Cure. (9 Marie Davis RN,IBCLC (used with permission), (www.lactationconsultant.info/cabbag ecure). Html diakses pada 15 September 2015.

Dinas Kesehatan Kota Kediri. (2015). Cakupan Ibu Nifas Kota Kediri. Jawa Timur: Dinkes.

Hill, P., S., \& Humenick, S., S. (1994). The occurrence of breast engorgement. J HumLact. 10:79-86.

Kemenkes RI. (2014). Riset Kesehatan Dasar. Jakarta: Kemenkes RI.

Marmi. (2012). Asuhan Kebidanan pada Masa Nifas "Peuperium Care”. Yogyakarta: Pustaka Pelajar.

Mars, Briggite, Fiedler, \& Chrystle. (2014). The Country Almanac of Home Remedies: Time-Tested and Almost Forgotten Wisdom for Treating Hundreds of Common Ailments, Aches \& Pains Quickly and Naturally. Beverly : Fair Winds Press.

Notoatmodjo, S. (2010). Metodeologi Penelitian Kesehatan. Jakarta: Rineka Cipta.

Novita, \& Regina, V., T. (2011). Efektifitas Paket Bunda Ceria Terhadap Rasa Nyeri Dan Pembengkakan Payudara Serta Produksi ASI Pada Ibu Post partum Di Jakarta.http://lib.ui.ac.id/file?file=digital/20282205T Regina VT Novita.pdfAccessed8 Sept 2016.

Nursalam. (2010). Konsep dan Penerapan Metodologi Penelitian Ilmu Keperawatan "Pedoman Skripsi Tesis dan Instrument Penelitian Keperawatan. Jakarta: Salemba Medika.

Rochimah, D., G. (2014). Efek Plasebo Kompres Daun Kol Dalam Mengatasi Pembengkakan Payudara Pada Ibu Post Partum (The Flacebo Effect Of Gabbage Sponge To Reduce The Breast Enggorgement In Post partum Mother).

Roberts. (2016). Comparison of chilled cabbage leaves and chilled gelpacks in reducing breast engorgement. JHumLact. 11:17-20.

Ririn. (2017). Penerapan Kompres Daun Kol Untuk Mengurangi Pembengkakan Payudara Pada Ibu Post partum di PMB Yustin Tresnowati Rowokele Kebumen.

Saleha, \& Sitti. (2009). Asuhan Kebidanan pada Masa Nifas. Jakarta: Salemba Medika.

SDKI. (2016). Cakupan Pemberian ASI di Indonesia. 
SDKI. (2016). Kejadian Mastitis dan Puting Susu Lecet di Indonesia.

Sugiyono. (2010). Statistika untuk penelitian. Bandung: Alfabeta.

Wahidah, N., dkk. (2014). Hubungan Pengetahuan Dengan Keterampilan Perawatan Payudara Pada Ibu Nifas Di Wilayah Kerja Puskesmas Kediri.

Zuhana, N. (2014). Perbedaan Efektifitas Daun Kubis dingin (Brassica OleraceaVar. Capitata) Dengan Perawatan Payudara Dalam Mengurangi Pembengkakan Payudara (Breast Engorgement) Di Kabupaten Pekalongan. 